\title{
ANALISIS BENTUK KELEMBAGAAN KELOMPOK TANI HUTAN RAKYAT DESA GATTARENG KECAMATAN MARIORIWAWO KABUPATEN SOPPENG
}

\begin{abstract}
(Institutional Form analysis Farmers of People's forests in the village of Gattareng the district
\end{abstract} of Marioriwawo Soppeng)

\author{
Yusran, Muhammad Alif K.S, Muh. Aswan, Adrayanti Sabar \\ Laboratorium Kebijakan dan Kewirausahaan Kehutanan, Fakultas Kehutanan, Universitas \\ Hasanuddin, Makassar Jl. PerintisKemerdekaan Km.10, Makassar \\ Email:yusranforest@yahoo.com
}

\begin{abstract}
This present research aims to identify related actor, in the formation and development farmers by the format rules, format relation and important role management of people forests in the village of Gattareng. The result of this research is to give inforaton for the farmers about Institutional Form analysis of the people forests by the form, format relation and important role management of the people forests. In addition, this research is conducted in October-November 2017. The research site is in gattareng village, Marioriwawo district, Soppeng regency. The methods of data collection used in this research are observation and interview. Based on research results it was concluded that related actor in establishment and development farmers of the people forests is the farmers, village head in the village of Gattareng, Forestry service in soppeng regency and the peopleof the farmers. In the formation Baccewe farmers the village of gattareng Mr. Bide is the had of the farmers make a formal role and activties by Baccewe farmers. The formal role of Baccewe Farmers is, the membership of farmers where in the membership must have a farmers, meeting for the membership of the farmers must twice for a week and all of the applicable regulation have a sanctions. Important role the management of people forests in the Village of Gattareng basically for public welfare of the people around the forests. Forestry service and agriculture servise in Soppeng regency do sustainable development of forest resources. By doing policy forest management optimize premises active engagement from people around the forest whose life depends on the forest. The goal is to improve people's welfare
\end{abstract}

Keyword: Farmers, Institutional, People Forests, ,

\section{PENDAHULUAN}

Hutan adalah salah satu sumberdaya alam yang penting, baik ditinjau dari segi ekonomi, ekologi, maupun sosial budaya. Undang-undang No. 41 Tahun 1999 tentang Kehutanan menjelaskan bahwa hutan adalah suatu kesatuan ekosistem berupa hamparan lahan berisi sumberdaya alam hayati yang didominasi oleh pepohonan dalam persekutuan alam lingkungannya, yang satu dengan yang lainnya tidak dapat dipisahkan (Satria, 2016).
Pengelolaan hutan rakyat umumnya belum mengacu pada aspek-aspek manajemen hutan secara lestari. Menurut Awang dkk.(2007) pengelolaan hutan rakyat masih berbasis pada tingkat keluarga karena setiap keluarga melakukan pengembangan dan pengaturan secara terpisah. Pada umumnya dalam pengelolaan hutan rakyat belum terbentuk organisasi yang professional dan belum ada perencanaan yang baik. Segala sesuatu yang berkaitan dengan pengelolaan hutan rakyat 
(penanaman, pemeliharaan, penebangan dan pemasaran) ditentukan oleh kebijakan masing-masing keluarga, sehingga tidak ada jaminan dari petani hutan rakyat terhadap kontinuitas pasokan kayu bagi industri.

Penguatan kelembagaan pengelolaan diperlukan untuk menjamin kelestarian hasil hutan rakyat sehingga terbentuk aturan internal yang mengatur sistem pengelolaan hutan yang disepakati oleh setiap anggotanya (Hindra 2006). Melalui kelembagaan itulah setiap pihak terkait dapat bersama-sama mengkaji dan mencari jalan keluar dari setiap masalah yang dihadapi. Pengaturan hasil hutan rakyat yang dilakukan melalui mekanisme kelompok dan musyawarah dapat membangun kesepahaman pemilik hutan rakyat dan kelompok, sehingga terwujud suatu kesepakatan dalam pengelolaan hutan menuju kepada kelestarian hutan rakyat dan kesejahteraan masyarakat.

Melihat pentingya peranan hutan, maka pemerintah menaruh perhatian yang besar terhadap pembangunan hutan rakyat. Pada praktek hutan rakyat dapat dikelompokkan atas hutan rakyat yang berbasisi pada komoditas kayu, hutan rakyat dengan komoditas non kayu seperti kakao. Hutan rakyat yang saat ini menjadi perhatian dalam pembangunannya adalah hutan rakyat yang berbasis pada komoditas non kayu, untuk ini pengembangan hutan rakyat di lapangan saat ini adalah lebih di fokuskan pada hutan rakyat kakao, hutan rakyat coklat dan hutan rakyat campuran (Adi, 2011).

Kelembagaan meliputi dua yaitu, kelembagaan pemerintah dan kelembagaan non pemerintah yang terlibat dalam pengelolaan hutan rakyat, dimana kelembagaan pemerintah sebagai suatu tatanan dan pola hubungan antara anggota masyarakat atau organisasi yang saling mengikat yang dapat menentukan bentuk hubungan antara manusia atau antara organisasi (Adi, 2011). Kelembagaan hutan rakyat yang strukturnya ada yang terwujud dan ada yang tidak terwujud, namun dalam penerapannya ada aturanaturan social yang mengikat, memeliki norma dan nilai social bagi pemilik lahan (Mayer dan Green, 2012).

Untuk memperoleh gambaran aktor yang terkait dalam pembentukan dan pengembangan kelompok tani hutan rakyat, maka dilakukan penelitian tentang kelembagaan hutan rakyat di Desa Gattareng Kecamatan Marioriwawo Kabupaten Soppeng.

\section{BAHAN DAN METODE}

\section{Alat dan Bahan}

Pada penelitian ini menggunakan alat dan bahan yang terdiri atas Kamera, Perekam Suara, Alat Tulis Menulis serta Kuisioner atau daftar pertanyaan.

\section{Metode Pelaksaan Penelitian}

Populasi dalam sampel yang diambil sebanyak 30 orang yang merupakan anggota kelompok tani yang memiliki lahan lebih dari 1 ha. Data yang diambil berupa data primer dengan metode observasi dan wawancara serta data sekunder dengan metode studi pustaka atau diambil dari buku-buku serta jurnal terkait penelitian.

HASIL DAN PEMBAHASAN

Aktor yang Terkait dalam

Pembentukan dan Pengembangan

Kelompok Tani Hutan Rakyat 
Berdasarkan hasil penelitian diketahui bahwa aktor yang terkait dalam pembentukan dan pengembangan kelompok tani hutan rakyat yaitu kelompok tani, kepala desa, Dinas Pertanian dan Dinas Kehutanan Kabupaten Soppeng.

\section{Tabel 1 : Daftar nama responden}

\begin{tabular}{|c|c|c|}
\hline No & $\begin{array}{l}\text { Keterangan } \\
\text { Responden }\end{array}$ & Tanggal \\
\hline 1 & Kepala desa & $21-08-2017$ \\
\hline 2 & Ketua kelompok tani & 21-08-2017 \\
\hline 3 & Sekertaris kelompok tani & 21-08-2017 \\
\hline 4 & $\begin{array}{l}\text { Seksi penanaman kelompok } \\
\text { tani }\end{array}$ & 21-08-2017 \\
\hline 5 & $\begin{array}{l}\text { Seksi pemeliharaan kelompok } \\
\text { tani }\end{array}$ & 2017 \\
\hline 6 & $\begin{array}{l}\text { Seksi penanaman kelompok } \\
\text { tani }\end{array}$ & 21-08-2017 \\
\hline 7 & $\begin{array}{l}\text { Staf dinas kehutanan Kab. } \\
\text { Soppeng }\end{array}$ & 2-09 2017 \\
\hline 8 & $\begin{array}{l}\text { Staf dinas pertanian Kab. } \\
\text { Soppeng }\end{array}$ & 6-09-2017 \\
\hline
\end{tabular}

Hasil wawancara terhadap responden tabel diatas disimpulkan sebagai berikut

\section{Kelompok Tani}

Kelompok tani menegelola hutan rakyat agar meniadakan sistem tanah lapang yang selama ini merugikan masyarakat. Selain itu diadakan juga sistem kerjasama yang berupa masukan program-program pemerintah baik yang berkaitan langsung dengan pembangunan hutan rakyat, sehingga kelompok tani mendapat bantuan dari Dinas Kehutanan Soppeng berupa bibit dan pembinaan tentang hasil yang sudah dicapai. Dengan terbentuknya kelompok tani Beccewe, maka hutan rakyat di Desa Gattareng dapat dikelolah dengan baik (wawancara responden 2, 3).

\section{Sejarah Terbentuknya Kelompok Tani Beccewe}

Pembentukan kelompok tani beccewe pada awal di berikan dana dari Pak
Kamaruddin Muhammad sehingga kelompok tani beccewe dapat terbentuk dan di berikan kepercayaan kepada Pak Bide sebagai ketua kelompok tani. Beliau tidak menginginkan adanya petani-petani yang hanya ingin memeperoleh keuntungan dengan cara apapun tanpa memikirkan petani lainnya yang kehidupannya berada di bawah taraf (wawancara responden 2, 3).

Kelompok tani Beccewe ini terbentuk pada tanggal 23 Agustus 1977, yang di prakarsai oleh Pak Kamaruddin Muhammad dengan jumlah kelompok tani 80 orang dengan luas lahan dengan luas lahan yang di garap mencapai 51,50 ha.

Tabel 2. Proses pembangunan Hutan Rakyat di Desa Gattareng Kec. Marioriwawo,

\begin{tabular}{|c|c|c|c|}
\hline No & Waktu & $\begin{array}{c}\text { Proses } \\
\text { pembangunan } \\
\text { hutan rakyat }\end{array}$ & Pihak yang berperan \\
\hline 1 & 1975 & $\begin{array}{l}\text { Awal untuk } \\
\text { mengubah } \\
\text { lahan yang } \\
\text { terlantar } \\
\text { menjadi hutan } \\
\text { rakyat }\end{array}$ & $\begin{array}{l}\text { Kamarullah } \\
\text { Muhammad }\end{array}$ \\
\hline 2 & $\begin{array}{c}23 \\
\text { Agustus } \\
1977\end{array}$ & $\begin{array}{l}\text { Terbentuknya } \\
\text { kelompok tani } \\
\text { beccewe }\end{array}$ & $\begin{array}{l}\text { dinas kehutanan } \\
\text { soppeng } \\
\text { pak Bide (ketua kelo } \\
\text { mpok tani Beccewe) }\end{array}$ \\
\hline 3 & $\begin{array}{c}25 \\
\text { Agustus } \\
1977\end{array}$ & $\begin{array}{l}\text { Bantuan bibit } \\
\text { sebanyak } \\
10.000 \text { bibit }\end{array}$ & Dinas kehutanan \\
\hline 4 & $\begin{array}{c}16 \\
\text { Novemb } \\
\text { er } 1997\end{array}$ & $\begin{array}{l}\text { Penanaman } \\
\text { awal, jarak } \\
\text { tanam } 5 \mathrm{~m} \mathrm{x} \\
5 \mathrm{~m} \\
\text { (sengong/Albi } \\
\text { zia Falcataria) } \\
\text { dan } 3 \mathrm{~m} \times 3 \mathrm{~m} \\
\text { (Coklat/ } \\
\text { Theobroma } \\
\text { cacao L.) }\end{array}$ & $\begin{array}{l}\text { Klp tani Beccewe, } \\
\text { Dinas pertanian }\end{array}$ \\
\hline
\end{tabular}




\section{Kelembagaan Kelompok Tani}

Kelembagaan kelompok tani pada hutan rakyat di Desa Gattareng memiliki tahapan dalam menegelola hutan rakyat antara lain kepemilikan lahan, pengelolaan lahan, pemeliharaan tanaman dan pengumutan hasil.

\section{Kepemilikan Lahan}

Lahan yang telah digarap sekarang 51,50 Ha dengan jumlah anggota 75 orang. Setiap anggota memiliki lahan 0,50 Ha sampai 1,00 Ha bahkan ada yang memiliki lahan seluas 2,00 ha untuk di kelolah, seiring berjalannya waktu Pak Bide memeperhatikan perkembanganperkembangan apa saja yang dihasilkan oleh anggotanya. Pengusulan dan pemberian surat pemeberitahuan pajak terutang pada setiap anggota did dukung oleh Kepala Desa Gattareng dan Dinas Kehutanan.

Tabel 3. Penggolongan responden berdasarkan luas lahan hutan rakyat.

\begin{tabular}{cccc}
\hline No & $\begin{array}{c}\text { Luas lahan } \\
\text { hutan rakyat }\end{array}$ & $\begin{array}{c}\text { Jumlah } \\
\text { responden }\end{array}$ & Persentase \\
\hline 1 & 0,50 ha & 48 & 64 \\
2 & 1,00 ha & 26 & 34,66 \\
3 & 2,00 ha & 1 & 1,33 \\
\hline & Jumlah & 75 & 100,00 \\
\hline
\end{tabular}

\section{Pengelolaan Lahan}

Salah satu tujuan awal pembuantan hutan rakyat ini adalah untuk memenuhi kebutuhan hidup masyarakat yang tidak mampu, sehingga dalam penerimaan anggota betul-betul dipilih yang masih dalam taraf kemiskinan. Dalam hal mengelolah lahan telah diberikan suatu kepercayaan bahwa mereka akan menglolah lahannya dengan baik, karena dalam hal ini semua anggota adalah masyarakat miskin maka mereka mengelola lahannya sendiri-sendiri tanpa diberikan kepada orang lain untuk mengelolahnya, namun jika ada lahan yang digarap atau dikelola oleh orang yang bukan merupakan miliknya maka diantara mereka telah terjadi suatu kesepakatan yang harus dipatuhi, seperti bagi hasil antara si pengelolah dan pemilik lahan.

\section{Pemeliharaan Tanaman}

Kegiatan yang pertama dilakukan adalah pembersihan lokasi oleh anggota secara gotong royong dengan mengguna cara yang manual, dan memebersihkan herbisida, pemasangan ajir dan pembuatan piringan tanaman.

\section{Pemungutan Hasil}

Hingga saat ini setelah kurang lebih 5 tahun berdirinya hutan rakyat tersebut, hasil yang diperoleh untuk tanaman Albizia Falcataria belum ada, namaun untuk tanaman semusim atau Theobroma cacao $L$. sudah diperoleh hasilnya, meskipun hanya di rasakan mulai pada tahun ke 3. Hasil yang diperoleh dari tanaman Theobroma cacao L. itu ada yang dijual dan ada yang dikomsumsi untuk dibibit kembali.

\section{Dinas Kehutanan dan Perkebunan Kabupaten Soppeng}

Dinas Kehutanan Kabupaten Soppeng memiliki peran tertentu untuk kelompok tani Beccewe yaitu memberikan sejumlah tanaman untuk di kelola pada hutan rakyat yang terdapat pada lokasi penelitian. Adapun tanaman yang di berikan kepada kelompok tani berupa tanaman Theobroma cacao L. (wawancaraa responden 7). Dinas Kehutanan juga memberikan bantuan bibit yang berjangka pendek untuk di tanam disela-sela 
tanaman kayu yang sudah di tanam sebelumnya dengan tujuan agar kelompok tani dapat memanfaatkan hasil dari hutan rakyat.

\section{Dinas Pertanian Kabupaten Soppeng}

Dinas Pertanian Kabupaten Soppeng mengemukakan bahwa kegiatan kelompok tani Beccewe adalah dengan memberikan berbagai bimbingan dan penyuluhan tentang kelembagaan yang dilaksanakan 2 kali dalam sebulan yang bertujuan untuk memperlancar kegiatan kelompok tani dalam mengembangkan hutan rakyat. Selain itu Dinas Pertanian juga berfungsi sebagai penghubung antara Dinas Kehutanan dengan kelompok tani, tentang hal-hal yang menyangkut dalam hal pencarian dana, serta membantu dalam hal memfasilitasi segala yang dibutuhkan kelompok. Penyuluhan yang diberikan berupa pemberian pengetahuan tentang pengembangan hutan rakyat, selain itu juga menanamkan rasa percaya diri dan semangat kepada semua anggota kelompok tani karena mereka biasanya, merasa malu akan diri dan keadaan yang sebagian dari anggota buta huruf. Memeberikan kenyakinan kepada mereka bahwa tidak selamanya orang buta huruf itu akan menjadi yang terbelakang.

\section{Kepala Desa}

Adanya Kepala Desa di lokasi penelitian ini sangat penting karena menjadi penghubung antara masyarakat, kelompok tani dan Dinas Kehutanan. Peranan seorang kepala desa perantara dalam mengubungkan individu atau kelompok dalam masyarakat yang membutuhkan bantuan atau layanan masyarakat,tetapi tidak tahu dimana atau bagaimana mendapat bantuan dari Dinas
Kehutanan, sehingga kepala desa memajukan pendapat kepada kelompok tani untuk membuat proposal untuk diajukan kepada Dinas Kehutanan dan memberikan bimbingan sehingga dapat menerima bantuan bibit. Bimbingan tersebut berupa memeberikan usulan meneegenai bagaimana struktur organisasi yang bisa dikembangkan dalam suatu organisasi atau kelompok, memberikan masukan mengenai apa saja yang pantas di kembangkan dalam suatu kelompok serta penanganan surat-surat, pembuatan anggaran dasar dan anggaran rumah tangga.

\section{Masyarakat Anggota Kelompok Tani}

Salah satu dari anggota masyarakat yaitu Bapak Heri yang juga merupakan sekertaris mengemukakan bahwa salah satu peran dari masyarakat adalah membangkitkan kesadaran anggota masyarakat. Membangkitkan kesadaran masyarakat agar mau berpartisipasi dalam kelompok tani dan dapat merasakan bagaimana perasaan mereka setelah terlibat dengan kelompok tani tersebut, karena sebelumnya tidak ada kesadaran dari masyarakat tentang bagaimana pembentukan dan pengembangan hutan rakyat untuk kedepannya, yaitu dengan cara mengajak mereka untuk ikut terlibat dalam pembangunan hutan rakyat, memeberikan pengertian tentang dampak dari pembangunan hutan rakyat (wawancara responden 2).

Bentuk Aturan Formal dan Kegiatan Kelompok Tani

\section{Bentuk Aturan Formal}

Berdasarkan hasil dari wawancara responden 1, 2 dan 3 bentuk aturan formal mencakup hal-hal seperti, keanggotaan 
kelompok tani, pertemuan rutin dari kelompok tani dan sanksi. Bentuk aturan formal dapat dilihat pada tabel berikut :

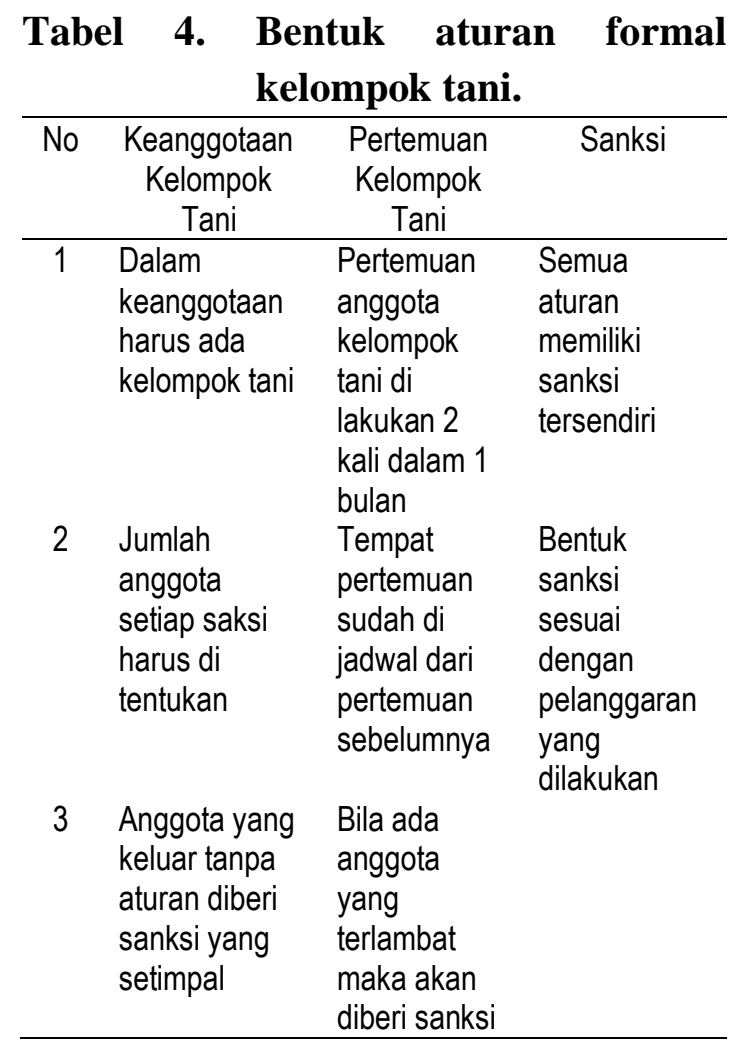

Bentuk aturan formal kelompok tani dari tabel di atas dapat ditarik kesimpulan bahwa setiap kelompok tani memiliki aturan masing-masing, bagi kelompok tani yang melanggar aturan dari kelompok tani itu sendiri maka akan diberi sanksi sesuai dengan pelanggaran yang dilakukan.

\section{Kegiatan Kelompok Tani}

Berdasarkan hasil dari penelitian kegiatan-kegiatan yang dilakukan oleh kelompok tani Beccewe adalah sebagai berikut:

\section{Pertemuan rutin kelompok tani Beccewe}

Berdasar hasil wawancara kelompok tani pertemuan rutin dilakukan 2 kali sebulan, dengan dihadiri penyuluhan dari Dinas Pertania serta Dinas Kehutanan
Kabupate Soppeng, yang dibicarakan dalam pertemuan ini adalah masalahmasalah teknis di lapangan, seperti bagaimana cara atauran-aturan dalam pemberian pupuk, masalah pemeliharaan, pemangkasan yang baik dan lain-lain yang dianggap perlu.

\section{Perbaikan administrasi kelompok yang difasilitas oleh pihak lain}

Kelompok-kelompok yang ada di masyarakat pada dasarnya merupakan modal sosial, karena adanya unsur norma dan nilai dalam kelompok tani serta adanya unsure kepercayaan yang merupakan suatu ciri modal social. Perbaikan-perbaikan administrasi yang dilakukan lebih banyak melibatkan pihak yang lain karena keadaan kelompok tani yang masih terdapat anggota yang buta huruf, maka perlu didampingi dalam urusan administrasi kelompok, dengan cara diberikan contoh bagaimana cara membuat administrasi yang baik dan benar. Salah satu contohnya adalah dalam pembuatan AD/ART yang di bantu oleh penyuluh petanian dan kehutanan.

Pembuatan kesepakatan atau aturan kelompok

Dalam kelembagaan kelompok tani beccewe tidak berdiri begitu saja, namun untuk mengelolah jalannya kelompok tani dibuatlah aturan baik tertulis maupun tidak tertulis yang secara umum mengatur masalah kewajiban dan hak anggota kelompok tani, aturan itu mereka sebut dengan Anggaran Dasar (AD) dan Anggaran Rumah Tangga (ART).

Pembuatan secretariat kelompok dan pondok kerja secara swadaya kelompok. 
Pembuatan secretariat kelompok yang dilakukan secara swadaya merupakan salah satu sarana dalam menyatukan setiap anggota kelompok, selain itu dengan adanya secretariat maka ada tempat bagi anggota kelompok tani dalam melakukan semua kegiatan kecuali kegiatan di lahan atau lapangan. Pembuatan pondok kerja yang juga dilakukan secara swadaya di lahan masing-masing yang digunakan sebagai tempat tinggal sementara diharapkan dapat memberikan kemudahan dalam kegiatan panen, pembersihan lahan dan merawat tanaman.

\section{Format Relasi}

Dari hasil penelitian aktor yang terkait dalam pembentukan dan pengembangan kelompok tani berdasarkan format relasi yaitu dinas kehutanan, dinas pertanian, kepala desa, kelompok tani dan masyarakat yang berada disekitar hutan dimana semuanya memiliki hubungan atau keterkaitan. Hubungan format relasi tersebut dapat dilihat pada gambar dibawah ini.

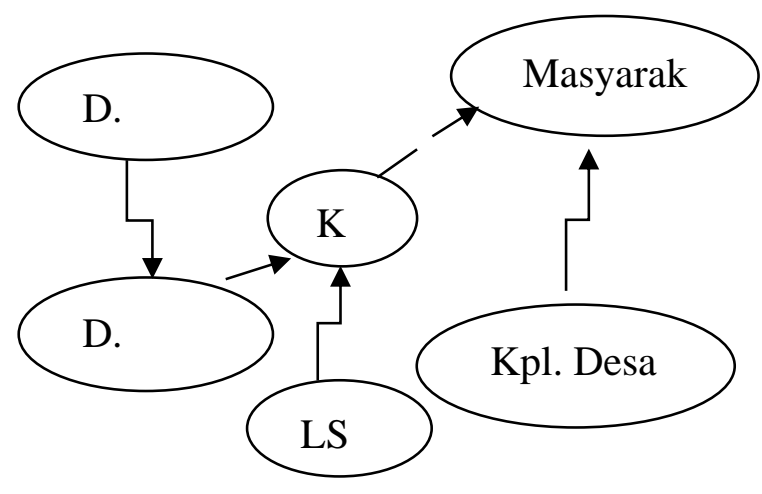

Gambar 2. Hubungan format relasi

Keterangan :

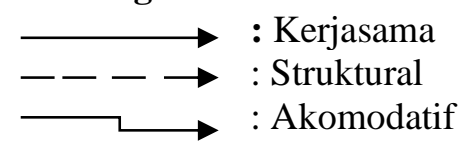

Kelompok tani Beccewe dalam pelaksanaan tidak berjalan sendiri namun ada bantuan dari LSM yang mendampingi sejak tahun 1978. LSM tersebut bernama Ampera soppeng dengan bantuan berups pengembangan kelembagaan kelompok tani. Keberadaan LSM ini sangat di perlukan karena banyak kegiatan-kegiatan yang membutuhkan bantuan dari LSM, diantaranya keranganya pengetahuan anggota dalam hal urusan administrasi, selain itu memberikan baerbagai penyuluhan-penyuluhan tentang apa itu hutan rakyat serta bagaimana pelaksanaanya yang baik dan bagaimana cara pengembangan hutan rakyat, selain itu juga menjadi pendamping sekaligus penghubung dengan Dinas Kehutanan dalam menyelesaikan berbagai urusan yang berhubungan dengan kebutuhan kelompok tani dalam pembangunan hutan rakyat.

Dinas Kehutanan dan Dinas Pertanian Kabupaten Soppeng bekerjasama dalam memeberikan informasi dan penyuluhan kepada kelompok tani. Di mana Dinas Kehutanan menyampaikan cara pembentukan dan pengembangan hutan rakyat dan Dinas Pertanian yang terjung langsung pada Desa Gattareng untuk menyangpaikan kepada kelompok tani Beccewe.

\section{Peran Penting Pengelolaan Hutan Rakyat di Desa Gattareng}

Peran penting pengelolaan hutan rakyat di Desa Gattareng pada intinya untuk kesejahtraan masyarakat sekitar hutan. Dinas Kehutatan dan Dinas Petanian Kabupaten Soppeng melakukan pembangunan sumberdaya hutan secara lestari. Dengan melakukan kebijakan 
pengelolaan hutan dengan mengoptimalkan keterlibatan aktif dari masyarakat sekitar hutan yang kehidupannya bergantung pada hutan. Tujuannya untuk meningkatkan kesejahteraan masyarakat. Hutan rakyat di Desa Gattareng menjadi salah satu solusi perekonomian dengan pemberdayaan masyarakat yang mempunyai lahan, mengatur ekosistemnya dan meningkatkan sisi komersialnya. Bagaimana kelompok tani Beccewe berkontribusi terhadap kebijakan pemerintah dan Dinas Kehutanan untuk membantu masyarakat sekitar hutan untuk meningkatkan hidup mereka melalui pemanfaatan hutan.

\section{KESIMPULAN}

Berdasarkan hasil penelitian disimpulkan bahwa aktor yang terkait dalam pembentukan dan pengembangan kelompok tani hutan rakyat, yaitu kelompok tani, kepala Desa Gattareng, Dinas Kehutanan Kabupaten Soppeng dan Dinas Pertanian Kabupaten Soppeng. Bentuk aturan formal Kelompok Tani Beccewe yaitu, peretemuan anggota kelompok tani dilakukan 2 kali dalam satu minggu semua peraturan yang ada dalam AD dan ART memiliki sanksi tersendiri, dan setiap anggota yang keluar dari Kelompok Tani Beccewe tanpa izin diberi saksi yang setimpal dengan pelanggarann yang dilakukan. Aktor yang terkait dalam pembentukan dan pengembangan kelompok tani berdasarkan format relasi yaitu Dinas Kehutanan, Dinas Pertanian Kabupaten Soppeng, Kepala Desa Gattareng, Kelompok Tani Beccewe, masyarakat yang berada disekitar hutan dan LSM Ampera soppeng semuanya memiliki hubungan atau keterkaitan satu sama lain. Peran penting pengelolaan hutan rakyat di Desa Gattareng pada intinya untuk kesejahtraan masyarakat sekitar hutan.

\section{SARAN}

Adapun saran kelompok tani Beccewe dalam mengelola Hutan Rakyat adalah sebagai berikut:

a. Metode pendampingan oleh Dinas Kehutanan dan Dinas Pertanian Kabupaten Soppeng dalam suatu kegiatan agar menggunakan metode pendampingan langsung di lapangan dalam proses pengelolaan Hutan Desa.

b. Dinas Kehutanan agar mealakukan monitoring rutin untuk melihat langsung kegiatan kelompok tani dalam mengelola potensi hutan rakyat Desa Gattareng.

\section{DAFTAR PUSTAKA}

Adi, I. R. 2011. Pemberdayaan, Pengembangan Masyarakat dan Intervensi Komunitas. ( pengantar pada pemikiran dan pendekatan praktis). Fakultas Ekonomi, Universitas indobesia. Jakarta.

Awang, S. A. 2002. Usaha Tani Hutan Rakyat dan Hutan Kemsyarakatan. Pusat Kajian Hutan Rakyat ( center for community forestry studies ). Fakultas Kehutanan. UGM.

Hindra B. 2006. Potensi dan Kelembagaan Hutan Rakyat. Prosiding Seminar Hasil Litbang Hasil Hutan 2006 "Kontribusi Hutan Rakyat dalam Kesinambungan Industri Kehutanan". Bogor (ID): Pusat Penelitian dan Pengembangan Hasil Hutan, Badan Penelitian dan Pengembangan Kehutanan, Departemen Kehutanan. 
JURNAL TENGKAWANG (2019)

Vol. 9 (1) : 42 - 50

Mayer, R. R. Dan Green, Wood, E. 1980. Rancangan Penelitian Kebijakan Sosial. Penerbit Pustekom Dikbud dan CV. Rajawali, Jakarta.

Satria, H.R. 2016. Pengelolaan Hutan Berbasis Masyarakat pada Hutan Nagari Di Jorong Simancung Nagari ALam Pauh Duo Kecamatan Pauh Duo Kabupaten Solok Selatan. Fakultas Hukum Universitas Andalas. Padang 